\title{
O TRATAMENTO DAS PAIXÕES NAS TRAGÉDIAS DE SÊNECA
}

\author{
ZELIA DE ALMEIDA CARDOSO* \\ Faculdade de Filosofia, Letras e Ciências Humanas da \\ Universidade de São Paulo
}

\begin{abstract}
RESUMO: Como um dos principais divulgadores da doutrina estóica em Roma, Sêneca deu freqüentemente às tragédias um caráter parabólico, utilizando-as como exempla que ilustram as conseqüências do descontrole dos sentimentos e das paixões. Nesse procedimento está um dos traços da originalidade do teatrólogo e da especificidade de seus textos trágicos. Inspiradas nas obras gregas, as peças dramáticas senequianas exploram mitos bastante conhecidos, mas que se submetem agora a um tratamento novo, sendo substituido o papel do fatum, o destino, pelo do furor, a loucura trágica. Para Sêneca, as paixões não controladas são o principal fator para o desencadear da catástrofe.
\end{abstract}

PALAVRAS-CHAVE: tragédia senequiana; filosofia estóica; furor; paixão; catástrofe.

A especificidade e a finalidade das tragédias de Sêneca têm sido objeto de numerosas controvérsias que se estendem da Idade Média ${ }^{1}$ a nossos dias, tendo-se intensificado no século $\mathrm{XIX}^{2}$ e adquirido uma coloração especial no momento presente, quando muitos estudiosos do assunto estão publicando trabalhos importantes sobre a obra do dramaturgo latino, conquanto por vezes algo discutíveis. ${ }^{3}$

Florence Dupont (Dupont, 1995, p. 9), por exemplo, em seu livro intitulado Les monstres de Sénèque, ao pretender propor uma "dramaturgia das tragédias de Sêneca" refuta a antiga idéia de que o teatrólogo tivesse composto textos trágicos apenas para a leitura e neles não vê nenhuma função didática (idem, p. 20). Considera-os apenas como obras que se prestam a espetáculos grandiosos, recheados de todos os ingredientes próprios da cultura romana. Apesar das inovações de leitura que propõe e de muitos aspectos positivos que podemos detectar no livro, não há dúvida de que a autora adota uma postura extremada, apresentando opiniões que podem ser contestadas. 
O tom filosófico dos textos trágicos, por exemplo, nos parece indiscutivel. Não é, evidentemente, a presença de máximas (sententiae) e de algumas digressões o que contribui para o estabelecimento desse tom. Como um dos principais divulgadores da doutrina estóica em Roma, Sêneca deu freqüentemente às tragédias um caráter parabólico, utilizando-as como exempla que ilustram as conseqüências do descontrole dos sentimentos e das paixões. $E$ as peças se prestam realmente a esse tipo de exemplificação.

O domínio e a racionalização dos sentimentos, a busca da impassibilidade diante das dores e agressões, a vivência plena da apátheia são os principais objetivos da ética estóica. Segundo a doutrina do Pórtico, ${ }^{4}$ o universo é um organismo único, um corpo vivo, alimentado por um sopro ígneo - a ratio, o logos - que lhe garante a coesão do todo. Esse sopro seria responsável pelo comando de tudo e procuraria eliminar a irracionalidade e a desordem. A física estóica considera o universo como um ente organizado, material e sujeito à rigorosa periodicidade dos ciclos, determinados por um princípio racional; a ética estóica, por sua vez, vê os homens como parte desse universo, sujeitos, portanto, às mesmas leis que o regem. A virtude humana seria a identificação com a natureza, a integração perfeita no mundo natural. $\mathrm{O}$ equilíbrio, necessário à manutenção da ordem, consistiria no controle do irracional, dos impulsos e das paixões.

Tais idéias, claramente expressas nos tratados senequianos, especialmente em De ira, De tranquillitate animi, De clementia, De beneficiis e nas Epistulae ad Lucilium, são sugeridas de forma poética nas tragédias.

Nesse procedimento está um dos traços da originalidade do teatrólogo e da especificidade de seus textos trágicos. Inspiradas nas obras gregas, ${ }^{5}$ as peças dramáticas senequianas exploram mitos bastante conhecidos, mas que se submetem agora a um tratamento novo. Nas lendas gregas, presentes nas tragédias áticas, em geral se atribui grande importância ao fatum - o destino. Nascido para cumprir uma sina, o ser humano se submete a forças exteriores e superiores ${ }^{6}$ que o impelem a percorrer um caminho pré-determinado, em detrimento, quase sempre, de sua própria vontade. Quando essas forças levam o ser humano a desviar-se de sua rota e a mergulhar numa situação conflitiva que lhe provoca a queda, configura-se a catástrofe, essencial à tragédia.

Sêneca aborda o fato trágico de maneira diferente. Se em Édipo (Oedipus) e, sob certos aspectos, em A loucura de Hércules (Hercules Furens) ainda notamos resquícios da tragédia grega no enfoque dado à catástrofe, em Fedra (Phaedra), Hércules no Eta (Hercules Oetaeus), Medéia (Medea), Agamêmnon (Agamemnon), Tiestes (Thyestes), 
As troianas (Troades) e As fenícias (Phoenissae), encontramos a visão do filósofo estóico. Para Sêneca a paixão não controlada, o furor, é o principal elemento desencadeador da catástrofe.

Florence Dupont faz um interessante estudo sobre o furor em Les monstres de Sénèque, ampliando significativamente idéias já anteriormente expressas em Le théâtre latin (Dupont, 1988, p. 51 seqs.). Para a autora, "a tragédia romana promete ao público romano o espetáculo de uma metamorfose de um homem em monstro" (Dupont, 1995, p. 55). Essa metamorfose é produzida pelo furor determinado por um excesso de sofrimento (dolor); o furor leva ao nefas, o crime hediondo, extraordinário, inexpiável, a profanação em seu grau mais alto.

Conforme o parecer de Florence Dupont, a conjugação dolor-furor-nefas é essencial à tragédia, ao "espetáculo da tragédia". O cumprimento do nefas, o crime que apresenta uma característica nitidamente desumana, é o fator da transformação do ser humano em monstro.

A passagem dolor/furor é minuciosamente explorada por Florence Dupont. Para ela, o sofrimento que gera o furor é sempre causado por um ferimento doloroso, por uma perda irreparável, havendo sempre um culpado da criação dessa situação. $\mathrm{O}$ acometido de dolor se sente "lesado em sua integridade social, privado de seu prestígio, desconsiderado aos olhos dos outros e a seus próprios olhos". A dor excessiva leva à cólera e esta evolui transformando-se no furor, a loucura trágica, a cegueira total, a perda de todo o discernimento.

Para Dupont, em Les monstres de Sénèque, a finalidade das tragédias senequianas é oferecer ao espectador o espetáculo desse caminho, dessa passagem. Tal espetáculo se inseriria numa ordem especial de espetáculos e ritos entre os quais se avulta pela importância os de natureza sacrificial. Na tragédia existe sempre um sacrifício, muito embora seu ritual seja pervertido já que quem o realiza está acometido de furor, a loucura em que se converte a paixão ou que com esta se identifica.

$\mathrm{O}$ estudo do tratamento dado às paixões por Sêneca já vem de longe. Léon Herrmann (Herrmann, 1924, p. 488 seqs.), em meados da década de 20, o analisou exaustivamente, mostrando que são três as que foram preferencialmente trabalhadas: a ambição, encarnada por Etéocles e Polinices em As fenícias, o ódio, presente sobretudo em Tiestes, mas também observado em Medéia, Hércules no Eta e Agamêmnon, e o amor, móvel principal do desencadeamento da catástrofe em Fedra, Medéia, Hércules no Eta e Agamêmnon e, de certa forma, também em Tiestes e em As troianas.

$\mathrm{Na}$ verdade, talvez pudéssemos reduzir essas três paixões apenas às duas primeiras, uma vez que o ódio não é jamais gratuito: nasce da ambição ou do amor, sobretudo deste último. 
O amor, em Roma, era concebido e tratado de forma bastante especial. Pierre Grimal (Grimal, 1963, p. 32-6), em L'amour à Rome, procura mostrar a posição do cidadão da Vrbs em relação a tal sentimento. Para o autor, o romano dos primeiros tempos era profundamente religioso e não podia deixar de ser sensível ao que considerava como o caráter sagrado do instinto sexual. Provam-no as práticas mágicas e as muitas reminiscências de rituais antigos relacionados com a união conjugal. ${ }^{7}$ No entanto, desde os primórdios da civilização romana, podemos observar a existência de uma consciência da antinomia gerada pelo instinto sexual. Bona Dea e Vênus representam dois pólos opostos, duas faces da mesma moeda. Mas enquanto Bona Dea, divindade primitiva do panteão itálico, configura as virtudes da mulher e sua capacidade de gerar, sendo cultuada com respeito e veneração, Vênus é vista como uma deusa alienígena, que simboliza a misteriosa e terrível força sedutora que emana do corpo feminino, sendo temida por seu poder anárquico e por sua capacidade de provocar paixões que podem inverter a ordem das coisas que o romano procurava preservar.

Casamento e geração de filhos são encarados em Roma como necessidades sociais e políticas. $\mathrm{O}$ casamento - que deve ser equilibrado, racional e desapaixonado - é legítimo e tem valor sacramental. ${ }^{8} \mathrm{O}$ iustum matrimonium, dignificante e sério, é sancionado pela lei e pela religião e em suas raízes está a idéia de serviço prestado à família e, por conseguinte, à pátria. É uma forma de estabelecerem-se alianças e fortificarem-se amizades e posições; é um instrumento para a conquista ou a consolidação do poder e para a fundação de uma societas, sendo-lhe, pois, fundamentais, o equilíbrio, a harmonia, o respeito mútuo das partes envolvidas. Baseado em princípios racionais, o casamento corresponde à solidez, imprescindível para a estabilidade do Estado.

O amor, contrariamente, é considerado como algo nocivo e perigoso. Quando desregrado e transformado em paixão, é catastrófico e suas conseqüências são funestas, devendo, portanto, ser evitado a qualquer preço e excluído do casamento.

Esses princípios, que foram consolidados pelo pensamento estóico, se afrouxam na época de Augusto. A decadência dos costumes se acentua com a excessiva permissividade ${ }^{9}$ e algumas leis são promulgadas com a finalidade de salvaguardar-se a antiga moral. ${ }^{10}$ Após a morte do princeps, entretanto, a permissividade volta a aparecer com mais força, caracterizando, de certa forma, os governos de Tibério, Calígula, Cláudio e Nero. ${ }^{11}$

É durante os anos em que esses príncipes dominam a cena política, que Sêneca adere ao pensamento estóico e escreve obras filosóficas e tragédias. E é na 
maioria destas que vamos observar a força do amor-paixão como elemento causador das grandes desgraças. ${ }^{12}$

Talvez seja Fedra a peça dramática mais importante para mostrar como o amor irracional pode acarretar a catástrofe. ${ }^{13}$ Valendo-se do antigo mito que explora a paixão da madrasta pelo enteado, sentimento que provoca a morte de ambos, Sêneca estuda e analisa a problemática do amor desenfreado.

No primeiro contato com a princesa de Creta, na segunda parte do prólogo da tragédia, o leitor-espectador a encontra num estado de profundo sofrimento, revelado na lamentação que faz. Como costuma ocorrer nas tragédias de Sêneca, a crise se instaura desde o início da ação. Fedra vive essa crise. À dor decorrente da ausência do esposo volúvel, a rainha acrescentara um outro mal: a paixão pelo jovem Hipólito. E ela fala dos males que suporta a custo:

Sed maior alius incubat maestae dolor.

Non me quies nocturna, non altus sopor

soluere curis: alitur et crescit malum

et ardet intus qualis Aetnaeo uapor

exundat antro. Palladis telae uacant

et inter ipsas pensa labuntur manus;

non colere donis templa uotiuis libet,

non inter aras, Atthidum mixtam choris,

iactare tacitis conscias sacris faces,

nec adire castis precibus aut ritu pio

adiudicatae praesidem terrae deam:

iunat excitatas consequi cursu feras

et rigida molli gaesa iaculari manu

Quo tendis, anime? Quid furens saltus amas?

Fatale miserae matris agnosco malum:

peccare noster nouit in siluis amor (Phae. 99-118)

Um sofrimento maior, no entanto, abate esta desgraçada.

Nem o descanso noturno nem o sono profundo

me libertam dos cuidados: é um mal que aumenta e cresce

e se incendeia no meu íntimo como o vapor do Etna

que escapa da cratera. Os teares de Palas são postos 
de lado e os fios da rocada me escapam das mãos;

não sinto vontade de honrar os templos com oferendas votivas;

nem de brandir, entre os altares, misturada ao coro das mulheres áticas, as tochas das iniciadas em cerimônias secretas; nem de aproximar-me com castas orações e piedoso ritual da deusa que preside a esta terra que lhe foi consagrada: o que me apraz é seguir as feras excitadas, em suas carreiras, e arremessar dardos de ferro com minha mão delicada. Para onde vais, ó minha alma? Por que, enlouquecida, procuras as florestas?

Reconheço a desgraça fatal de minha pobre mãe:

foi nos bosques que nosso amor aprendeu a errar. ${ }^{14}$

As imagens utilizadas por Sêneca na lamentação de Fedra mostram o caráter incontrolável da paixão: o amor exaltado é semelhante às chamas ou ao vapor que escapa das crateras dos vulcões; acarreta sofrimentos intoleráveis e provoca mudanças de atitude e de comportamento: insônia, sono agitado, languidez, descaso pelo trabalho doméstico e pelas práticas religiosas, desejo de praticar atos violentos, no recôndito das florestas, como se nelas houvesse uma espécie de abrigo.

Inicialmente Fedra atribui ao fatum, o destino, a louca paixão que a domina, o malum fatale: fora atingida pelo mal que atingira Pasífae e que a conduzira a uma zooerastia viciosa, contrária à razão e aos costumes; mais adiante a rainha culpa Vênus pelo desencadeamento da paixão:

Stirpem perosa Solis inuisi Venus, per nos catenas uindicat Martis sui suasque, probris omne Phoebeum genus onerat nefandis: nulla Minois leui defuncta amore est, iungitur semper nefas (Phae.124-128)

Vênus, detestando a estirpe do odiado Sol, se vinga, por nosso intermédio, das cadeias impostas a Marte e a ela; esmaga com opróbrios nefandos toda a geração de Febo: nenhuma filha de Minos se satisfaz com um amor tranqüilo; ele sempre se associa a um crime hediondo. 
Fedra se dá conta de que se encaminha para a consumação de um nefas, um ato abominável, contrário à lei divina, à moral, às leis da religião e da natureza. A utilização do antigo vocábulo nefas, em lugar de crimen ou scelus, é bastante sintomática. Nefas é a forma negativa de fas, palavra que se liga a fari pelo sentido. Se fas significa "a expressão da vontade divina”, "a ordem dos deuses”, "a justiça divina”, "o direito divino", "o que é permitido", "o que é justo", nefas significa "o que é ímpio, sacrílego, execrável, detestável, maldito”.

A ama de Fedra - o alter ego da heroína -, encarnando inicialmente o bom senso e a ponderação e possibilitando o conhecimento da eclosão do conflito, assume uma atitude freqüente entre as amas da tragédia clássica ${ }^{15}$ e ministra conselhos à filha de leite, procurando reconduzi-la ao caminho da razão e da dignidade:

Thesea coniunx, clara progenies Iouis, nefanda casto pectore exturba ocius, extingue flammas neue te dirae spei praebe obsequentem: quisquis in primo obstitit pepulitque amorem tutus ac uictor fuit; qui blandiendo dulce nutriuit malum, sero recusat ferre quod subiit iugum (Phae.129-135) Esposa de Teseu, descendência ilustre de Júpiter, arranca, o mais depressa possivel, esse amor nefasto de teu peito puro, extingue as chamas e não te deixes dominar por uma esperança funesta. Quem contraria e combate o amor, desde o início, tem a segurança da vitória; quem nutre esse mal, acarinhando-o docemente, muito tarde se recusa a suportar o jugo que sofre.

O discurso exortativo se presta a algumas observações. Ao dirigir-se a Fedra, utilizando os epítetos "esposa de Teseu" e "descendência ilustre de Júpiter", a ama parece querer chamá-la de volta a seus deveres conjugais, convidá-la a assumir um comportamento digno de sua nobre ancestralidade; ao referir-se ao amor que domina a rainha, considerando-o nefandus, evoca as idéias contidas no sentido de nefas; ao demonstrar que a paixão avassaladora pode ser arrancada no momento em que se manifesta mas que acaba por subjugar totalmente a pessoa apaixonada se for 
alimentada, procura valer-se, embora sem sucesso, da desejável eficiência de uma filosofia doméstica. Para ela, Fedra tem possibilidades de escolher um caminho.

Essa abertura é comum em Sêneca e consiste num de seus traços característicos. O teatrólogo romano, ao elaborar suas personagens trágicas e ao colocá-las em situações de conflito, decorrentes da submissão às paixões, permite-lhes a opção. Denis e Elisabeth Henry (Henry, 1985, p. 59 seqs.), no terceiro capítulo de The Mask of Power, intitulado "The evil will", analisam a questão da escolha e do arbítrio com bastante propriedade. Para eles, quando Fedra se dispõe a insistir em sua paixão proibida ela sabe o que está fazendo. Tenta desculpar-se, reconhece que está dominada pelo furor, mas, em sua resposta à ama, responsabiliza o deus Amor, ao qual todos se submetem:

\section{[...] Quod memoras scio}

uera esse, nutrix; sed furor cogit sequi

peiora. Vadit animus in praeceps sciens

remeatque frustra sana consilia appetens.

Sic, cum grauatam nauita aduersa ratem

propellit unda, cedit in uanum labor

et uicta prono puppis aufertur uado.

Quid ratio possit? Vicit ac regnat furor

potensque tota mente dominatur deus.

Hic uolucer omni pollet in terra patens

laesumque flammis torret indomitis Iouem (Phae.177-187)

[...] Sei que o que lembras é verdade,

minha nutriz; mas a loucura me faz seguir o caminho pior.

Mesmo consciente, minha alma se dirige ao abismo

e volta, buscando inutilmente uma inspiração saudável.

Da mesma forma, quando o nauta conduz o barco,

dominado pelas ondas adversas, seu trabalho se torna vão

e a popa vencida é levada pela água que a arrasta.

De que adianta a razão? A paixão vence e reina

e o deus poderoso domina minha mente.

Alado, ele estende seu poder por toda a terra

e incendeia o próprio Júpiter, ferido por seu fogo indômito. 
Mais uma vez o amor é comparado às chamas devastadoras e a paixão a algo que não pode ser controlado: à nau à mercê da força dos vagalhões.

A ama não se esquiva da resposta. Embora mais adiante, ao dirigir-se a Hipólito, se refira também ao poder do amor, ${ }^{16}$ no momento em que responde a Fedra, quase como uma verdadeira mãe, assume um tom cético em relação ao caráter divino desse poder, o tom de descrença na força dos deuses, que ocorre por vezes nas tragédias de Sêneca: ${ }^{17}$

Deum esse amorem turpis et uitio fauens

finxit libido, quoque liberior foret

titulum furori numinis falsi addidit.

[. . . ]

uana ista demens animus asciuit sibi

Venerisque numen finxit atque arcus dei (Phae.195-197; 202-203)

Foi o desejo culposo, que favorece o vício, quem inventou

que o amor é um deus; para ser mais livre, acrescentou

à paixão o nome de uma falsa divindade.

[... .]

Um espírito demente se atribuiu a criação dessas mentiras

e inventou a divindade de Vênus e o arco do deus.

Por duas vezes o teatrólogo, que não hesita em considerar o deus-menino como uma falsa divindade (numen falsum), emprega a forma finxit (inventou, moldou, criou, "fingiu") para indicar a ação daqueles que atribuíram a Cupido e a Vênus a responsabilidade no desencadear do sentimento do amor.

As palavras da ama não cumprem sua função. Nem os argumentos racionais nem os patéticos de que se vale mais adiante são suficientemente fortes para demover a rainha apaixonada. Fedra reconhece o erro que está cometendo mas só encontra uma saída honrosa para escapar da luta que enfrenta: matar-se.

A decisão da mulher enamorada provoca uma reviravolta na tragédia, modificando totalmente o comportamento da ama. Diante da perspectiva de um suicídio da filha de criação, ela se deixa contaminar pelo furor, abandona as idéias estóicas e se decide a procurar Hipólito e a tentar convencê-lo da necessidade de amar. 
Como todos os sentimentos desmedidos e desenfreados, a paixão de Fedra tem uma força demolidora e um caráter contagiante. Venceu a rainha, destruindolhe a virtude, o senso do dever e a vontade de viver. Vence agora a ama, incapaz de tolerar a idéia de que Fedra possa vir a matar-se. Contamina mais adiante Hipólito, quando este ouve a declaração da madrasta, e Teseu, que, ao saber da falsa verdade, amaldiçoa o filho, causando-lhe a morte. $\mathrm{O}$ furor gera outros furores e a um crime nefando que parece desenhar-se no início se somam outros crimes: sedução, delação, calúnia, maldição, suicídio.

Depreende-se do texto a mensagem estóica, vazada nas sugestões: os sentimentos e impulsos devem ser controlados para que se garanta o equilíbrio e a ordem universais; as paixões não dominadas acarretam catástrofes sobre catástrofes, alastram-se, contaminam; o amor-paixão, como uma loucura ou uma doença, levando o homem ao caminho do vício, é nocivo e deve ser rigorosamente combatido, sobretudo quando se reveste de um caráter proibido ou criminoso.

Fedra é por excelência a tragédia do amor-dolor, do amor-furor, do amor que não aceita a recusa e se transforma em agente do nefas.

Nas outras tragédias que antes mencionamos Sêneca trabalha com outras modalidades de amor trágico, construindo uma verdadeira galeria de personagens furiosas cuja loucura foi causada pelo amor, pelas conseqüências da paixão. Se em Hércules no Eta, o crime não chega propriamente a consumar-se, pois que Dejanira, a esposa de Hércules, desiste da idéia de matar o esposo, substituindo-a pela administração de um filtro mágico, em Medéia, em Agamêmnon e em Tiestes, os crimes são cometidos em nome do amor.

Medéia permite que se transforme em furor o ciúme que sente pelo esposo infiel, ciúme que se agrava com o ultrage do abandono e do repúdio e a faz cometer um crime hediondo e inconcebível ao matar não apenas a noiva de Jasão mas os próprios filhos que gerara. Clitemnestra se dispõe a eliminar Agamêmnon movida por uma série de razões: a paixão por Egisto, a lembrança do sacrifício de Ifigênia, o ciúme. Atreu tardiamente se resolve a vingar-se do crime cometido por Tiestes que seduzira a esposa do irmão na esperança de conquistar o poder. Em todos esses casos os crimes são marcados pela violência, pela crueldade, por terem como objeto pessoas da mesma casa, parentes, consangüíneos. Em todos esses casos, também, existe uma possibilidade de escolha. A pessoa acometida de furor é alertada para o caráter do crime que está em vias de cometer. Conselheiros eventuais, como amas ou cortesãos, tentam mostrar que existem outros caminhos. Há luta interior que se processa no íntimo dos criminosos em potencial e que se reflete no seu físico e nos 
seus atos. ${ }^{18}$ Mas eles se incitam a si próprios para adquirir coragem e cometer o nefas.

Dejanira se incentiva no momento em que se sente enfraquecer:

[...] Quid stupes, segnis furor?

Scelus occupandum est: perage dum feruet manus (H.O. 434-435)

[...] Por que te deténs, furor pusilânime?

É preciso que te deixes tomar pelo desejo do crime; age enquanto tuas mãos se abrasam.

Medéia, depois de invocar os deuses conjugais e as sombrias divindades subterrâneas, pedindo-lhes assistência e proteção, se dirige a seu próprio espírito, procurando dar-lhe força:

Per viscera ipsa quaere supplicio uiam,

si uiuis, anime, si quid antiqui tibi

remanet uigoris; pelle femineos metus

et inhospitalem Caucasum mente indue (Med.40-43)

Procura, em tuas próprias vísceras, o caminho da vingança;

se estás viva, ó minh'alma, se algo de teu antigo vigor

subsiste, despoja-te dos temores femininos

e introduz em tua mente a hostilidade do Cáucaso.

Clitemnestra, ao entrar pela primeira vez em cena, faz um esboço de seu conflito interior e se dirige a sua própria pessoa, numa exortação à ação:

Quid, segnis anime, tuta consilia expetis?

Quid fluctuaris? Clausa iam melior nia est.

Licuit pudicos coniugis quondam toros

et sceptra casta uidua tutari fide:

periere mores, ius, decus, pietas, fides

et qui redire cum perit nescit pudor;

da frena et omnem prona nequitiam incita:

per scelera semper sceleribus tutum est iter (Aga.108-115) 
Por que vais em busca de uma decisão certa, espírito fraco?

Por que vacilas? O caminho do bem está fechado.

Em outros tempos te foi permitido manter honrados, como uma casta viúva, o cetro e o leito nupcial.

Faliram os costumes, o direito, o decoro, a piedade, a fidelidade

e o pudor que, quando se perde, ninguém sabe como reaver.

Solta os freios e incita qualquer espécie de perversidade.

Para os crimes, o caminho do crime é o mais seguro.

Apesar de suas hesitações, conforme a expressão de Denis e Elisabeth Henry (Henry, 1985, p. 58), "uma escolha deliberada se faz": a ação dramática se desenvolve e a catástrofe se cumpre.

Um sentimento equivalente ao que domina tais mulheres determina as ações nefandas de Atreu na tragédia Tiestes. Se, no caso de Fedra, Dejanira e Medéia, é o amor desprezado que se transforma em ódio, se no de Clitemnestra é o ciúme que se conjuga com nova paixão, o ódio de Atreu se desenvolve a partir do conhecimento da infidelidade da esposa, seduzida por Tiestes. Surgindo em cena no primeiro episódio, Atreu recrimina-se a si próprio considerando-se fraco, sem ação, sem nervos e sem vingança; recrimina-se porque se contenta em lamentar-se pela perfídia do irmão, que não hesitara em violar as leis sagradas do parentesco e do matrimônio. Como Clitemnestra e Medéia, Atreu incentiva seu próprio ânimo, buscando a coragem que lhe faltava:

Age, anime, fac quod nulla posteritas probet, sed nulla taceat. Aliquod audendum est nefas atrox, cruentum, tale quod frater meus suum esse mallet: - scelera non ulcisceris, nisi uincis (Thy. 192-195)

Anda, minh'alma, faze o que nenhuma posteridade aprove, mas também o que nenhuma cale. Deve ser cometido o crime atroz, sangrento, que meu irmão gostaria de ter cometido.

Não se pode vingar um delito sem ultrapassá-lo.

Os mesmos ingredientes, em todos esses textos, se acomodam em jogos diferentes: dolor, furor, possibilidade de escolha, conselhos desprezados, nefas. 
Em As troianas o descontrole dos sentimentos no que diz respeito ao plano amoroso não se configura às claras como o elemento imediato que provoca a tragédia: o rapto de Helena levado a termo por Páris poderia ser considerado como um móvel distante, uma causa remota, lembrada contudo por Hécuba, Andrômaca e pela própria Helena ${ }^{19}$ no decorrer da tragédia.

A catástrofe presente no texto, representada inicialmente pela escravização e pelo sorteio das mulheres e amplificada pela morte de Políxena e de Astíanax tem causas próximas: decorre da derrota de Tróia, da pseudo-aparição do espírito de Aquiles, da pusilanimidade de Agamêmnon e das palavras de Calcante, o portavoz de Apolo. A causa primeira da guerra, no entanto, embora Hécuba assuma a culpa por ter gerado Páris, foi a paixão ilegítima do prícipe troiano e o conseqüente seqüestro da rainha de Esparta.

Sêneca se vale das tragédias, portanto, como dissemos, para ilustrar princípios da doutrina estóica. E elas assumem, assim, uma função moralista e didática. Só a razão bem conduzida confere ao homem a apátheia de que ele necessita para integrar-se no cosmos. As paixões, a exacerbação dos sentimentos, a liberação dos instintos, o amor sem legitimidade são os elementos desencadeadores das catástrofes: provocam a desordem, o desequilíbrio, as desgraças e o caos.

\section{Notas}

* Professora Doutora de Língua e Literatura Latina do Programa de Pós-Graduação em Letras Clássicas da FFLCH-USP.

1 Thomas Curley, em The nature of Senecan drama (Curley, 1986, p. 25), se refere a Nicholas Trevet, que comentou a obra de Sêneca na Idade Média e considerou que o filósofo "deu ensinamento éticos a mentes doentes por meio das atrações oferecidas pelas obras dramáticas".

2 Léon Herrmann (Herrmann, 1924, p. 233 seqs.), com base em estudos anteriores realizados por J. Lipse (1607), W.A. Swoboda (1825-1830), F. Leo (1878-1879), G. Richter (1902), H. L. Lehmann (1853) e muitos outros, analisa diversas teorias sobre as finalidades das tragédias, no capítulo III de Le théâtre de Séneque. Algumas vêem nos textos uma finalidade meramente retórica (é o caso das que foram formuladas por F. Jacobs, Nisard, Patin e Leo); outras, uma finalidade política (as de Ranke e Boissier), religiosa (Ranke, Birt, Simcox), pedagógica (Birt, Brakman), paródico-crítica (Bernhardy, Lindskog, Moricca, Schaefer), ou dramático-literária. Para o autor, embora haja outros elementos mesclados à poesia, tais como verdades morais e máximas políticas, a finalidade principal das tragédias é a dramático-literária (idem, p. 246 seqs.). 
3 Florence Dupont, por exemplo, publicou em 1995 um texto bastante "revolucionário" sobre o assunto: Les monstres de Sénèque (Dupont, 1995).

4 Cf. Arnold, E.V. Roman stoicism. Cambridge, Cambridge University Press, 1911; Bovis, A. La sagesse de Sénèque. Paris, Aubier, 1948; Levi, A. Storia della filosofia romana. Firenze, 1949; Brun, J. Les Stoïciens. Paris, PUF, 1957; Brun, J. Le Stoïcisme. Paris, PUF, 1958; Boyancé, P. "Le stoïcisme à Rome”. In: Actes du VII Congrès de l'Association Guillaume Budé. Aix-en-Provence, 1963.

5 Muitas foram as fontes de que se valeu Sêneca, na composição de suas tragédias. Além dos grandes trágicos gregos - Ésquilo, Sófocles e Eurípides - que as inspiraram diretamente, Sêneca teve a seu dispor a tragediografia latina do período republicano e imperial (os textos de Névio, Ênio, Pacúvio, Ácio, Vário), a épica de Virgílio, as Metamorfoses de Ovídio e as obras filosóficas dos estóicos que o precederam.

6 A esse respeito consulte-se o ensaio de Auerbach (Auerbach, 1971, p. 271-291) intitulado "O príncipe cansado", inserido em Mimesis, no qual, a pretexto de analisar um trecho do drama histórico Henrique IV, de Shakespeare, o autor faz uma interessante reflexão sobre as características da tragédia.

7 No santuário de Vélia, onde se adorava Mutanus Titanus, o deus era representado por um órgão sexual masculino, símbolo do poder fecundador; os falos estavam presentes no lares, as vestais o cultuavam e as procissões fálicas se realizavam com periodicidade determinada; os Liberalia, festividades em homenagem a Liber Pater, consagravam o poder do deus da germinação; os versos fesceninos, a linguagem obscena empregada em algumas solenidades religiosas, o culto de Priapo acentuavam essa tendência.

8 Maiores informações sobre o casamento romano podem ser encontradas em Fowler (Fowler, 1964, Cap. V).

9 A esse respeito consultem-se as obras de André Piganiol (Piganiol, 1954, p. 222 seqs.) e Guglielmo Ferrero (Ferrero, 1949, p. 173 seqs).

10 Vejam-se, por exemplo a Lex Iulia de maritandis ordinibus e a Lex Iulia de adulteriis.

11 A esse respeito consulte-se a obra de Bloch (Bloch, 1922, p. 76 seqs).

12 Para maiores informações sobre o caráter do amor para os estóicos veja-se o trabalho de Maria Cristina Pimentel intitulado Quo uerget amor? (Pimentel, 1993, p. 23 seqs.).

13 Para maiores informações sobre o assunto, veja-se Cardoso, Z. A. "Elementos filosóficos na Fedra de Sêneca" (Dezotti, 1987. p. 43-61).

14 Os trechos em latim foram transcritos do texto estabelecido por Léon Herrmann e publicado pela Société d’Édition "Les Belles Lettres” (Sénèque, 1967 e 1971). As traduções são de nossa responsabilidade.

$15 \mathrm{Um}$ interessante estudo sobre as amas na tradição clássica foi feito por S. Vilatte (Vilatte, 1991) e publicado em L'Antiquité Classique.

16 Saepe obstinatis induit frenos Amor/ et odia mutat "O amor freqüentemente subjuga os obstinados/ e lhes modifica o sentimento do ódio" (Phae. 574-575).

17 No texto das tragédias de Sêneca há algumas insinuações à não-existência dos deuses convencionais. Veja-se, por exemplo, Med. 1026-7 e Tro. 402-8. 
18 Veja-se, por exemplo, a descrição de Dejanira feita pela ama: O quam cruentus feminas stimulat furor,/ cum patuit una paelici et nuptae domus!/Scylla et Charybdis Sicula contorquens freta / minos est timenda, nulla non melior fera est./ Namque ut reluxit paelicis captae decus/ et fulsit Iole qualis innubis dies/ purisue clarum noctibus sidus micat,/ stetit furenti similis ac toruum intuens/ Herculea coniunx; feta ut Armenia iacens/ sub rupe tigris hoste conspecto exilit/ aut iussa thyrsum quatere conceptum ferens/ Maenas Lyaeum, dubia quo gressus ferat/ haesit parumper (H.O. 233-245) "Oh! Que furor sanguinário estimula as mulheres / quando a mesma casa se abre para a esposa e para a amante!/ Sila e Caribdes, causando o arrebentamento das vagas da Sicília,/ são menos temíveis; as feras são mais afáveis que ela./ Desde que aqui reluziu a beleza da concubina escravizada/ e que Iole brilhou como um dia sem nuvens/ ou como os astros luzentes que cintilam numa noite clara,/ a esposa de Hércules, com seu olhar ameaçador,/ se tornou semelhante a uma mulher demente. Ela é como uma trigresa armênia,/ que, parindo filhotes sob um rochedo, se arremessa à vista do inimigo;/ ou como a mênade em delírio, obrigada a agitar os tirsos de Lieu,/ que pára um momento, sem saber para onde ir”.

19 Hécuba, ao recitar o prólogo, evoca por duas vezes a figura de Páris, embora não chegue a acusá-lo ou a responsabilizá-lo. Na primeira procura assumir a culpa por ser a genitora do culpado e recorda o sonho profético que havia tido (Tro. 33-40); na segunda se refere ao Ida e ao julgamento de Páris (Tro. 65-66), sugerindo, sem o dizer, a responsabilidade de Vênus. Andrômaca, ao discutir com Helena, vê na rainha de Esparta (e no seu casamento) a causa da guerra (Tro. 891-898). Helena, por sua vez, ao defender-se, numa bela apologia, atribui a culpa a Páris (Tro. 917-922).

\section{REFERÊNCIAS BIBLIOGRÁFICAS}

ARNOLD, E. V. Roman stoicism. Cambridge: Cambridge University Press, 1911. AUERBACH, E. Mimesis. Tradução de S. F. Sperber. São Paulo: EDUSP/Perspectiva, 1971.

BLOCH, G. L'empire romain: évolution et décadence. Paris: Flammarion, 1922.

BOVIS, A. La sagesse de Sénèque. Paris: Aubier, 1948.

BOYANCÉ, P. Le stoïcisme à Rome. Actes du VII Congrès de l'Association Guillaume Budé. Aix-en-Provence, 1963.

BRUN, J. Les Stoïciens. Paris: PUF, 1957;

-. Le Stoïcisme. Paris: PUF, 1958;

CARDOSO, Z. A. A contrução de As troianas de Sêneca. Tese de Doutoramento. São Paulo: USP, 1976 (Policopiada).

-. Elementos filosóficos na Fedra de Sêneca. In: DEZOTTI, M. C. C. (Org.). Fedra/ Hipólito. A permanência de um mito clássico. Araraquara: UNESP/SBEC, 1987. p. 43-61. 
-. A lenda de Édipo na literatura latina. In: BRANDÃO, J. L. (Org.). O enigma em Édipo Rei e outos estudos de teatro antigo. Belo Horizonte: UFMG/CNPq, 1985. p. $176-88$.

CURLEY, T. The nature of Senecan drama. Roma: Edizioni dell'Ateneo, 1986.

DEZOTTI, M. C. C. (Org.). Fedra/Hipólito. A permanência de um mito clássico. Araraquara: UNESP/SBEC, 1987. p. 43-61.

DUPONT, M. Le théâtre latin. Paris: Armand Colin, 1988.

-. Les monstres de Sénèque. Paris: Belin, 1995.

FERRERO, G. Nouvelle Histoire Romaine. Paris: Hachette, 1949.

FOWLER, W. W. Social life at Rome (in the age of Cicero). London: McMillan, 1964.

HENRY, D. \& E. The mask of power. Seneca's tragedies and imperial Rome. Chicago: Bolchazy-Carducci Publishers/ Warminster, Wiltshire, Aris \& Phillips, 1985.

HERRMANN, L. Le théâtre de Sénèque. Paris: "Les Belles Lettres”, 1924.

LEVI, A. Storia della filosofia romana. Firenze: 1949.

PIGANIOL, A. Histoire de Rome. Paris: PUF, 1954.

PIMENTEL, M. C. Quo uerget furor? Aspectos estóicos na Phaedra de Sêneca. Lisboa: Colibri, 1993.

SÉNEQUE. Tragédies. Texte établi et traduit par L.Herrmann. Paris: "Les Belles Lettres", 1971. t. I.

-. Tragédies. Texte établi et traduit par L. Herrmann. Paris: "Les Belles Lettres", 1967. t. II.

VILATTE, S. La nourrice grecque. L'Antiquité Classique. Louvain-la-Neuve, t. LX, p. 5-28, 1991.

CARDOSO, Zelia de Almeida. Le traitement des passions dans les tragédies de Sénèque.

RÉSUMÉ: Comme un des principaux divulgateurs de la philosophie stoïque à Rome, Sénèque a souvent donné à ses tragédies un caractère parabolique, en les utilisant comme des exempla qui illustrent les conséquences du manque de contrôle des sentiments et des passions. Dans ce procédé on voit un des traces de l'originalité de l'auteur. Inspirées des oeuvres grecques, les 
tragédies de Sénèque exploitent des mythes assez connus en leur donnant un traitement nouveau par le remplacement de la fonction $d u$ fatum par celle de la passion non contrôlée, du furor, l'élément principal qui déclanche la catastrophe.

MOTS-CLÉS: tragédie sénéquienne; philosophie stö̈que; furor; passion; catastrophe. 